\title{
O BATE-PAPO EDUCACIONAL: UM GÊNERO POTENCIAL PARA PRÁTICAS SOCIAIS E ATIVIDADES PEDAGÓGICAS EM AULAS A DISTÂNCIA
}

\author{
SUSANA CRISTINA DOS REIS \\ suzi_30@yahoo.com
}

\begin{abstract}
Discussions about the process of teaching and learning online have been the focuses of different researches in the field of applied linguistics (Menezes, 2001; Warschauer,1996; Warschauer e Kern, 1998; Warshauer \& Meskill, 2000; Tavares, 2001). In this article will be discussed how teachers beliefs and thoughts should be changed in order to work in an online environment. It also emphasizes the perspective of using genres in the classroom and specially digital genres to promote learner's skills. At last, the educational chat will be analised and described as a genre which belongs to the system of online genres.Activities related to the use of the educational chat will be suggested as well as a potencial genre that can promote social practice and pedagogical tasks in a virtual classroom.
\end{abstract}

\section{INTRODUÇÃO}

O uso de tecnologias no ensino de Línguas Estrangeiras (LEs) tem sido foco de diversas pesquisas na área de Lingüística aplicada (Menezes, 2001; Warschauer,1996; Warschauer e Kern, 1998; Warshauer \& Meskill, 2000; Tavares, 2001). Em pesquisa anterior (Reis, 2004), destaquei a necessidade dos saberes necessários ao professor de LE para atuar em um contexto digital. No entanto, ainda há grande necessidade de se discutir mais sobre como ensinar LEs a distância com base em gêneros e de que forma é possível propor atividades pedagógicas para a prática da língua inglesa por meio de gêneros digitais.

Pesquisas na área de gêneros discursivos têm destacado a necessidade de orientarmos o ensino da linguagem com base em gêneros, a fim de compreendermos as diferentes manifestações da linguagem, bem como esta possibilita o engajamento dos sujeitos em discursos da contemporaneidade (Meurer, 2002). Com base nessa afirmação, as discussões propostas neste artigo visam a enfatizar como o professor de LE pode possibilitar o engajamento dos aprendizes quanto ao uso de gêneros em sala de aula. O foco está em destacar características de um gênero digital - o Bate-papo educacional - e de que maneira esse gênero pode ser explorado em sala de aula a fim de agilizar a aprendizagem da língua-alvo dentro de uma abordagem sócio-interacionista de ensino de línguas.

Neste artigo, primeiramente, discuto a necessidade de transformação de cren- 
ças e atitudes de professores quanto ao uso do meio digital na sala de aula, na seqüência, apresento o que a literatura recente tem apontado sobre o uso de gêneros na sala de aula. Na última seção, considerações sobre o gênero o bate-papo educacional (doravante BPE) - que faz parte do sistema de gêneros "aula a distância" são apresentadas, bem como atividades que podem agilizar a dinâmica pedagógica realizada por intermédio desse gênero em aulas a distância.

\section{CONTEXTUALIZANDO A PRÁTICA DE ENSINO DE LE NO CONTEXTO ELETRÔNICO}

Ao analisar teoricamente as vantagens que o uso de gêneros digitais oferecem ao processo de ensino-aprendizagem, pude verificar que contribuições pedagógicas e várias analogias têm sido propostas como forma de evidenciar aspectos importantes para implementações do uso de gêneros digitais no ensino. Murphy (2000) apresenta uma analogia muito interessante entre as "aventuras" vivenciadas por Robinson Crusoe e "as aventuras" que envolvem aprender e ensinar LEs no contexto digital. Nesse caso, a analogia não retrata especificamente o uso do gênero bate-papo, mas propõe alguns aspectos com relação ao papel do professor frente ao uso de tais gêneros. Neste artigo gostaria de salientar alguns aspectos que parecem comuns à discussão proposta.

Murphy (2000) em seu trabalho dá um enfoque especial à metamorfose que tanto o professor quanto o aluno sofrem ao tentar se adaptar ao contexto online para o ensino e aprendizagem de LEs. A autora salienta que Crusoe, ao chegar na ilha, preocupou-se em transformar o ambiente que chegou como explorador em um parecido ao que ele tinha na civilização. Para que o ambiente da ilha apresentasse tudo de que ele precisava, Crusoe decidiu investir na adaptação do contexto local, buscando organizar, ordenar, medir, mapear, legalizar, explorar, administrar, regularizar e marcar os ambientes que ele tinha ao seu dispor. A partir dessas tarefas realizadas, Crusoe possibilitou a metamorfose do ambiente da ilha.

Ao recontar a história de Crusoe, Tournier (1972 apud Murphy, 2000) expande-a na direção da construção de uma parábola que retrata a forma como Crusoe constrói também o seu próprio mundo subjetivo. Segundo o autor, em determinado momento da história, Crusoe chega a um outro ambiente da ilha que não lembrava em nada aquele da civilização. Nesse momento, "o explorador", ao invés de mudar o ambiente, decidiu fazer o inverso, ou seja, adaptar-se ao ambiente. Agora foi ele quem mudou sua aparência, sua relação com os habitantes nativos e seus hábitos diários nessa ilha. Essa metamorfose influenciou o seu estado de espírito, pois tornou-o mais reflexivo, deixandoo mais feliz e em paz para viver na ilha sem precisar transformá-la (Murphy, 2000).

A experiência de Crusoe, por analogia, mostra, de diferentes maneiras, as estratégias às quais, instintivamente, recorremos quando enfrentamos situações e ambientes novos em geral. Mapeamos o território e, para enfrentar as novas adaptações, comparamos o novo com aquilo que conhecemos, contamos com 
os conhecimentos que nos são familiares e dependemos deles; buscamos recriar o ausente na tentativa de modelar algo novo que mantém relação com o que conhecíamos no passado. No entanto, como na segunda experiência de Crusoe, a interação com o novo, por vezes, demanda que nos desliguemos do passado e dos paradigmas que orientaram o nosso modo de pensar e agir sobre a realidade (Murphy, 2000).

Se pensarmos na Internet como um ambiente a ser explorado, parece importante refletirmos sobre o que esse ambiente oferece de recursos potenciais que podem ser explorados, especialmente, no processo ensino-aprendizagem de Inglês como Língua Estrangeira. Embora os recursos do meio virtual ainda precisem ser explorados de uma forma mais eficiente no contexto pedagógico, isso só acontecerá se os professores puderem repensar suas crenças, opiniões, teorias e práticas de modo a adequá-las a esse ambiente de ensinoaprendizagem. Caso isso não aconteça, repete-se a experiência primeira de Crusoe, ou seja, os professores ficam esperando que uma simples transposição de suas crenças para o meio eletrônico solucione os problemas encontrados.

Entendo que o uso da Internet só será pedagogicamente produtivo se em vez de "transformar" o ambiente sem considerar as especificidades do meio em questão, os professores conhecerem esse novo ambiente de ensino/aprendizagem e adaptarem-se a esse contexto diferenciado de interação. Para tanto, é necessário definir ações e estratégias, mapear os territórios existentes, para que, ao interagir na web, os professores possam ser capazes de expandir suas crenças e concepções, bem como, torná-las compatível com as exigências que o ambiente eletrônico impõe.

No entanto, isso normalmente não acontece. Para muitos professores, o ambiente virtual tem se configurado apenas como um local para a transposição de materiais projetados para a veiculação de textos impressos. Muitos aventureiros cibernéticos ainda acreditam que a simples digitalização do material que é utilizado em sala de aula convencional, ao adaptá-los ao contexto eletrônico possa se tornar "eficientes" e favorecer o processo de aprendizagem. No entanto, pesquisas têm apontado que esse tipo de iniciativa não gera necessariamente bons resultados (Braga, 2001; Lacombre, 2000).

Braga (2001), por exemplo, afirma que:

é tentador querer transpor para a situação de rede as opções metodológicas que deram bons resultados na situação presencial. No entanto, a transposição para o meio eletrônico requer que a produção pedagógica e textual sofra alterações e adaptações específicas, dadas às diferenças que existem entre o texto/exercício no papel e o texto/exercício na tela.

Além dessas alterações, esse meio também requer uma grande transformação na forma como os participantes concebem, produzem e divulgam seus conhecimentos. Sabemos do impacto que as novas tecnologias têm causado no processo ensino/aprendizagem, das vantagens e desvantagens que esse meio oferece aos aprendizes de LE. Assim, faz-se necessário propor uma a- 
bordagem de ensino online que permite o uso de gêneros, tendo em vista as pesquisas recentes que enfatizam essa questão.

\section{MAPEANDO A LITERATURA: O QUE SÃO GÊNEROS E COMO EXPLO- RÁ-LOS NO ENSINO DE LÉ?}

$\mathrm{Na}$ literatura, o trabalho do russo Mikhail Bakhtin torna-se referência. No entanto, o conceito, proposto por Bakhtin (1992:279), de que gêneros são tipos relativamente estáveis de enunciados, não parece suficiente quando compreendemos que gêneros ocorrem em determinados contextos e envolvem diferentes agentes que o produzem e o consomem (Meurer, 2005:82).

Carvalho (2005: 131), ao discutir o conceito proposto por Bakhtin, afirma que o pesquisador já se distanciava da oração como unidade de análise e, para a autora, Bakhtin reconhecia o enunciado como unidade de comunicação verbal. Para Carvalho, Bakhtin já pensava muito além do nível da sentença, pois o pesquisador se preocupava com o próprio ato de comunicação, com a atividade social, marcada pelo diálogo, e possibilitada pela interação (Carvalho, 2005:132). Na concepção de Carvalho (idem), gêneros são responsáveis por organizar a experiência humana, atribuindo-lhe sentido. Para a autora, gêneros são os meios pelos quais vemos e interpretamos o mundo e nele agimos (idem:133).

Para Bazerman (2005) a maioria dos gêneros tem características de fácil reconhecimento que sinalizam a espécie de texto que são, e para esse pesquisador, essas características, freqüentemente, estão internamente relacionadas com as funções principais ou atividades realizadas pelo gênero. Esse reconhecimento de gêneros e de suas características textuais ou funcionais, no entanto, depende das atividades que a linguagem exerce em tais contextos de interação, e não apenas pelo tipo de texto que o compõe. Ao analisar a afirmação de Bazerman, observo que há uma certa preocupação pela comunidade acadêmica em reconhecer gêneros, pois ao que parece é por meio desse reconhecimento que os participantes de um determinado contexto social poderão compreender melhor como produzir e consumir gêneros.

Já Marcuschi (2005 apud Bazerman, 2005:10) enfatiza que gêneros são formas típicas de usos discursivos da língua desmembradas de formas anteriores, pois os gêneros nunca surgem num grau zero, mas num veio histórico, cultural e interativo dentro de instituições e de atividades preexistentes. Se levarmos em consideração que gêneros surgem em um dado contexto sóciohistórico e cultural, na atual sociedade midiática, principalmente na Internet, os gêneros digitais surgem e são adaptações de outros gêneros pré-existentes.

Segundo Araújo (2005:107-109), gêneros do cotidiano estão transmutando para a web, ou seja, eventos sociais transmutam-se da esfera social para a esfera eletrônica. No estudo especifico de Araújo, o pesquisador sugere que a conversa cotidiana transmutou-se para a web, na forma de bate-papo eletrônico. Para Araújo, essa transmutação gerou um novo gênero, de natureza híbrida que funde oralidade e escrita em um mesmo suporte. Além disso, a con- 
versa cotidiana permite que a linguagem usada em tal contexto sofra modificações ou assuma nova formatação, pois o texto produzido materializa o gênero digital, permeado de oralidade e de formas semióticas, e passa a ser reconhecido pelos seus participantes como bate-papo social.

Além dessas discussões sobre o reconhecimento de gêneros digitais, outra questão é com relação ao uso de gêneros digitais na sala de aula de LE. Gêneros tais como páginas pessoais e diários virtuais têm sido explorados como recursos potenciais para a prática de ensino de línguas, principalmente, para o desenvolvimento da comunicação escrita (Dillon\&Gushrowski, 2000; Chandler, 1998; Abreu, 2005; Ruiz, 2005; Komesu, 2005). Além desses aspectos centrais, nos estudos citados anteriormente, os pesquisadores preocupam-se em descrever os movimentos retóricos desses gêneros digitais, assim como as ações comunicativas realizadas pelos participantes por meio de gêneros digitais. Komesu (2005) argumenta, em seu artigo, sobre as práticas de escrita que os sujeitos fazem sobre si ao divulgar a si mesmo por intermédio do gênero blog. Nesse artigo, a autora também problematiza que fatores humanos poderiam estar relacionados às novas práticas de produção textual que são mediadas por intermédio desse gênero discursivo.

No atual contexto sócio-histórico, não podemos ignorar que os adolescentes são os principais usuários de gêneros digitais, pois fazem uso de diferentes gêneros para se comunicar na web. Nesse sentido, é responsabilidade do professor intermediar o ensino com base em gêneros e possibilitar que seus alunos façam uso adequado desses gêneros ao produzir linguagem. Se concebermos linguagem como prática social, segundo Meurer (2002:10), a linguagem se inscreve como um sistema mediador de todos os discursos e tem como função estabelecer a interação entre os participantes, assim como possibilitar a construção do conhecimento. Assim, é papel do professor intermediar essa prática, bem como possibilitar a interação entre os participantes a fim de que produzam conhecimentos e façam uso da linguagem por meio da produção e do consumo de gêneros.

Com relação ao ensino da linguagem, Meurer (2002) salienta a necessidade do aprendiz desenvolver a criticidade como requisito básico para o engajamento na vida social contemporânea. Para o pesquisador, é fundamental também que a escola desenvolva habilidades comunicativas em seus alunos por meio da prática de ensino ao explorar gêneros discursivos e ao inseri-los em diferentes atividades sociais. Essas questões propostas por Meurer, ainda que previstas para o ensino presencial, podem ser aplicadas ao ensino a distância, visto que é preciso desenvolver nos participantes a criticidade e as habilidades comunicativas dos alunos. A Internet possibilita essa interação e agiliza a comunicação entre os pares, pois permite o acesso a recursos midiáticos e favorece o contato dos aprendizes com falantes de LEs.

Para Meurer (2002:11), é papel do professor orientar os alunos na compreensão de como ocorrem as diferentes manifestações da linguagem, ao possibilitar a discussão e análise de gêneros em que são focalizados sobre o que se fala, quem fala e como se fala. Tendo em vista essas orientações, acredito 
que, ao delimitarmos com nossos alunos quem são os participantes de um gênero em específico e de que modos às pessoas se engajam em tais situações comunicativas, isso poderá orientar o engajamento dos alunos nas atividades sociais e possibilitará que a produção escrita seja mais objetiva e ofereça melhores resultados ao interagir por meio da linguagem.

A possibilidade de interagir pela língua escrita em contextos eletrônicos, permite aos estudantes aprender a língua, sobre a língua e através da língua (McCarthy \& Carter, 1994: 134), pois o aluno tem a sua disposição diferentes contextos de interação e pode aplicar seus conhecimentos ao comunicar-se. Em vista disso, parece necessário que se ensine a LI com base em gêneros, partindo do uso, pois, conforme proposto por Halliday (1994), a linguagem pode ser vista como um processo de escolha pela qual os aprendizes serão capazes de usá-la no meio social em que estão inseridos. Inserir-se nesses ambientes, possibilita promover a aprendizagem e a interação do aprendiz a fim de que seja capaz de se comunicar efetivamente na língua-alvo.

Embora o uso de gêneros digitais na sala de aula ofereça vantagens para o ensino, muitos professores ainda não são letrados digitalmente para interagir e propor tarefas que explorem o uso desses gêneros com eficiência. Para isso é importante que se relate experiências e estratégias que orientem, tanto ao professor quanto ao aluno, sobre como explorar diferentes gêneros digitais na sala de aula, de modo que a inserção dos participantes em tais contextos sociais os auxilie na aquisição e no compartilhamento de conhecimentos.

Na próxima seção descrevo o que pesquisadores tem proposto sobre o gênero Bate-papo educacional.

\section{O GÊNERO BATE-PAPO EDUCACIONAL (BPE).}

O 'educacional chat' ou 'bate-papo educacional' (BPE) é um gênero que visa à comunicação virtual de um determinado grupo de participantes de um curso online, em que são enfatizados aspectos pedagógicos para o ensinoaprendizagem de um determinado tema ou função lingüística.

O gênero BPE tem sido usado em diferentes cursos de línguas na modalidade a distância ou semi-presenciais que explorem o uso desse gênero na prática de ensino de LEs (Collins \& Ferreira, 2004; Araújo, 2004; Abreu, 2005; Reis, 2004). No entanto, pouco ainda se sabe como o professor deve atuar e que tipos de tarefas podem ser propostos ou discutidos quando o gênero BPE é usado para a prática e uso da linguagem que favoreça o processo de ensino-aprendizagem a distância. Todavia, ainda que esses aspectos tenham sido pouco discutidos, principalmente, com relação às questões metodológicas que podem auxiliar o professor a interagir com eficiência, para Abreu (2005:87), conhecer e dominar o uso do chat educacional é um aspecto necessário para torná-lo eficaz na educação.

Abreu (2005) discute algumas características do gênero BPE e sugere que esse gênero, por se constituir dentro do contexto da Internet, sofre adaptações 
a cada nova situação. Para a autora, o bate-papo usado para fins educacionais, provavelmente, está se constituindo e se modificando, ao mesmo tempo em que constitui e modifica os sujeitos/agentes da situação.

Horton (2000), citado em Abreu (2005), apresenta algumas características do bate-papo educacional e alguns procedimentos para um melhor uso desse gênero em cursos virtuais, entre as quais destacam-se as necessidades de: 1) promover um espaço de trocas de idéias rápidas, espontâneas e emocionais; 2) determinar a quantidade de participantes em um BPE, bem como organizar o horário e aos objetivos do BP; 3) o professor "ditar" o ritmo da aula, para garantir a participação de todos e tentar solucionar os problemas.

Embora as orientações de Horton sejam interessantes para o professor iniciante com relação ao uso do BPE na sala de aula, discordo do autor ao propor que o professor deve "ditar" o ritmo da aula. Acredito que o ritmo da aula e, mais especificamente, o ritmo de aprendizagem e da interação do aluno devem ser respeitados pelo professor, pois é papel do professor, ao interagir por meio do gênero BPE, encontrar alternativas e estratégias que auxilie os alunos no seu processo de aprendizagem em contextos digitais.

Nesse trabalho, Horton (2000 apud Abreu, 2005:89) também enfatiza que bate-papo social e educacional tem características distintas e que os professores e os alunos, ao fazer uso desse gênero, terão que se ajustar ao bate papo educacional, a fim de que seu uso seja eficaz na educação.

Em pesquisa realizada, para a disciplina de Gêneros Discursivos, oferecida no Programa de pós-graduação em Letras, em 2006, na Universidade Federal de Santa Maria, analisei e descrevi o gênero bate-papo educacional com vistas a identificar algumas características desse gênero que foi utilizado em um curso de inglês a distância, na Universidade Federal de Santa Maria. Desse estudo, algumas considerações parecem importantes destacar, as quais reproduzo abaixo:

a) O BPE é o gênero mais usado pelos participantes de cursos de inglês a distância, pois favorece a comunicação e aprendizagem da LI. Por intermédio desse gênero podem ser discutidos os conteúdos do curso, as funções lingüísticas que possibilitam a aprendizagem e o engajamento do aprendiz na comunicação em LI.

b) No curso analisado, os alunos tinham acesso aos conteúdos por intermédio do site (http://www.ufsm.br/labler/webenglish) e esses conteúdos estavam organizados em 10 aulas e abordavam diferentes tópicos. A metodologia de ensino proposta no curso visava que os alunos acessassem os conteúdos previamente ao encontro virtual, para que ao interagir no BPE, tivessem a possibilidade de praticar a língua alvo.

c) O curso analisado insere-se em uma perspectiva de ensino que o objetivo é a linguagem como prática social, por isso o contexto de interação proporcionado pelo gênero BPE constituía-se em um contexto interativo, tendo em vista a aprendizagem real e colaborativa que favorecesse a discussão e participação dos alunos no engajamento das tarefas e no 
uso da linguagem em LI.

d) As ações realizadas nesse contexto de interação visavam à comunicação e o desenvolvimento da interação em LI, pois se esperava que os alunos participassem das seções de BPE com vistas à aprendizagem da língua alvo. A linguagem, nesse contexto, torna-se essencial para a interação e aprendizagem dos alunos, além disso, é a ferramenta mediadora das ações comunicativas que os participantes usam para se engajar na produção textual e discursiva do gênero em foco.

Essas questões abordadas acima, ainda que reflitam a análise de um curso em específico, podem ser aplicadas a nossa prática de ensino, principalmente se levarmos em consideração o contexto de situação e de cultura em que se realiza o gênero bate-papo educacional.

É preciso enfatizar que a importância do contexto para a realização desse gênero é fundamental para que ele se realize. $O$ contexto ajuda definir o gênero BPE, pois esse gênero configura-se a partir da interação dos participantes no contexto eletrônico, que mediado por uma ferramenta ou um programa de bate-papo, permite o engajamento de vários participantes no contexto de produção do gênero BPE e dá suporte para que o gênero se realize a partir do uso da linguagem.

Os textos produzidos por meio do gênero BPE são resultantes das atividades de interação que visam à prática e o uso da LI. Ao fazer uso do BPE, é fundamental definir tarefas previamente, para que o participante, ao interagir por meio do BPE, tenha a possibilidade de transformar a informação recebida em conhecimento.

Alguns tipos de tarefas que trazem bons resultados são aquelas que direcionam os alunos para a discussão de conteúdos específicos no BPE. Por exemplo, os alunos deveriam conversar sobre suas preferências, com relação às músicas, comidas, programas de TV, etc. Além disso, essas tarefas exigiam a participação de outros colegas, Uma atividade proposta era que cada participante deveria entrevistar um segundo colega com relação a suas preferências pessoais.e depois de realizada essa interação, relatar as escolhas desse colega à professora e aos demais participantes, não necessariamente por meio do bate-papo, mas em um texto mais organizado por e-mail.

Alunos iniciantes, ao participar de uma seção de BPE, devem ter como objetivo praticar funções da linguagem, tais como se apresentar uns aos outros, falar sobre a família, amigos, preferências ou ao relatar eventos passados e atividades do dia-a-dia, etc. Essas funções podem previstas para que o aluno, ao comunicar-se por intermédio do gênero BPE, faça uso da língua escrita e seja capaz de expressar quem ele é, o que ele faz ao atuar na sociedade, com quem ele convive, com quais pessoas interage e quais são as atividades sociais que participa.

No gênero BPE, o texto produzido na tela do computador configura-se na forma de diálogos, e esses diálogos são compartilhados por todos os participantes. No entanto, o participante do gênero determina se quer ou não que sua 
atuação seja reservada ou aberta a todos. Em uma aula presencial isso somente seria possível se o aluno solicitasse à professora que a conversa fosse em particular. Além disso, essa possibilidade de falar reservadamente também permite que os participantes sintam-se à vontade para expressar as suas dificuldades.

Os participantes assumem diferentes papéis na seção de BP, em algumas situações os alunos não desempenham apenas o papel de aprendiz, mas atuam como colaboradores, pares mais capazes, que fazem parte de uma sociedade, que possuem identidade e que pertencem a um grupo social. Ao interagir com os outros colegas ou com visitantes no BPE, eles comunicam-se e podem conhecer um pouco mais com quem estão interagindo.

O uso do BPE possibilita ao participante interagir em LI. Neste contexto os alunos produzem linguagem ao descrever quem são os participantes, o que fazem, onde vivem etc. Em cursos a distância, o BPE pode ser usado também para que o aluno esclareça suas dúvidas com relação à dinâmica do curso, a localização de tarefas, bem como ele deve proceder para realizar determinadas tarefas do curso, ou ainda com relação aos conteúdos propostos no curso, sobre expressões, vocabulários, aspectos gramaticais e funcionais da linguagem.

O papel da linguagem no gênero BPE é constitutivo, pois a língua escrita torna-se mediadora da comunicação entre os participantes do gênero, pois é por meio da linguagem que o processo interativo entre os participantes acontece de forma dialógica, em um canal de mensagem que é totalmente gráfico e que usa a língua escrita e gráfica para desenvolver a interação entre os participantes.

Ao analisar o contexto e os eventos, vejo que o desenvolvimento da comunicação e a execução de tarefas por intermédio do gênero BPE delimitam os textos produzidos nos BP. Conseqüentemente, fatos sociais foram produzidos, ou seja, os fatos sociais constituíram-se a partir da criação de textos que são produzidos pelos participantes de um gênero (Bazerman, 2005:21). Nesse sentido, o espaço virtual, gerado pelo gênero BPE, constituí-se no contexto de situação em que os participantes realizam atividades, ações e práticas discursivas.

\section{CONSIDERAÇÕES FINAIS}

Para Bazerman (2005:23), numa sala de aula, o trabalho de um professor freqüentemente serve para definir gêneros e atividades, e, fazendo isso, criar oportunidades e expectativas de aprendizagem. Aplicando essa afirmação ao presente artigo, acredito que o trabalho do professor virtual "rompe com as barreiras da sala de aula", principalmente quando pensamos em uma aula a distância. Ao trabalhar com gêneros digitais, o professor, além de definir gêneros e atividades, cria as oportunidades de acesso e de interação e, conseqüentemente, de construção da aprendizagem.

Se pensarmos na Internet como uma instituição que possibilita diversas ativi- 
dades que podem ser executadas por intermédio de gêneros, acredito que cada participante dessa instituição determinará suas ações e as atividades de interação. Para adolescentes, as atividades podem ter funções especificas, tais como comunicar-se com os colegas, procurar namorado(a), jogar online, mandar mensagens instantâneas pelo MSN, escrever no Blog ou criar comunidades no Orkut. Já um participante adulto pode não ter os mesmos objetivos de interação. Por exemplo, um adulto que faz parte do contexto acadêmico e que é ativo em uma instituição de ensino, poderá usar a Internet para entrar em contato via e-mail com os alunos ou com outros pesquisadores da mesma área de interesse, fazer pesquisas acadêmicas localizando referências bibliográficas, coletando material para a produção de atividades didáticas, ensinar e aprender online etc.

Todavia essas ações possam estar interligadas por um mesmo contexto eletrônico, na Internet as atividades realizadas pelos participantes dependem de um sistema de gêneros constituídos por um conjunto de gêneros que organizam a produção e a circulação de outros gêneros, ou seja, em uma aula a distância, há vários outros gêneros que a constituem e para que essa se realize é necessário entender a aula a distância como um sistema de gêneros.

Nessa perspectiva, precisamos compreender que os participantes desse sistema de gênero assumem papéis diferentes ao participar de diferentes conjuntos de gêneros. Ao fazer uso desses gêneros, os participantes exploram de forma organizada contextos diferentes de interação e isso depende da atividade social em foco. Nesse sentido, o uso de gêneros permitirá relações padronizadas de ações mediadas pela linguagem, de consumo e de produção de textos que sejam necessários em um contexto digital.

A Internet gera muitas possibilidades de ação, portanto, essas ações devem ser guiadas e orientadas pelo trabalho do professor. Nesse sentido, é interessante explorar o uso do gênero BPE na sala de aula, tanto presencial, quanto a distância, visto que esse contexto real de interação e comunicação agiliza a prática da escrita e favorece a aquisição da língua alvo, pois ao interagirmos, usamos palavras, e as palavras não apenas significam, mas fazem coisas (Austin apud Bazerman, 2005:25).

O gênero BPE é híbrido, seja com relação ao conteúdo e suas funções e atividades sociais, ou seja, os movimentos retóricos desse gênero são identificáveis, mas modificam-se a cada seção. Esse gênero, no entanto, realiza-se a partir da interação dos participantes e o texto produzido nesse contexto depende do objetivo comunicativo de cada aula proposta. O gênero BPE também depende de uma ferramenta de bate-papo para realizar-se, pois a tecnologia em si mesmo, não garante a realização do gênero, mas por meio da ferramenta e do suporte possibilitado pela Web é que as atividades sociais, as práticas discursivas permitem a interação entre os participantes do gênero BPE. 


\section{BIBLIOGRAFIA}

ARAÚJO, J. C. R. de. A conversa na Web: O estudo da transmutação em um gênero Textual. In: Marcuschi, L.A et al. Hipertexto e gêneros digitais, Rio de Janeiro: Lucema, 2004.

ABREU, L. S. O Chat educacional: o professor diante desse gênero emergente. In Gêneros textuais: reflexões e ensino, 2005.

BAKHTIN, M. Estética da criação verbal. São Paulo: Martins Fontes, 1992.

BAZERMAN, C.; A. P. DIONÍSIO; J. C. HOFFNAGEL. (Orgs.). Gêneros

textuais, tipificação e interação. São Paulo: Cortez, 2005.

BRAGA, D. Aprendendo a Ler Na Rede: A Construção de Material Didático para Aprendizagem Autônoma de Leitura em Inglês. Disponível em: http://www.abed.org.br/antiga/htdocs/paper visem/denise bertoli braga.htm.

Acesso em Set. 2003

CHANDLER, D. Personal HomePages and the Construction of Identities on the Web.

Disponível em:[http://www.aber.ac.uk/media/Documents/short/webident.html]. Acesso em dez 2000.

CHRISTIE, F. Genre theory and ESL Teaching: a systemic functional perspective. In: Tesol Quarterly, vol 33, o 4, Winter, 1999

CARVALHO, G. Gênero como ação social em Miller e Bazerman: o conceito, uma sugestão metodológica e um exemplo de aplicação. In: J. L. Meurer, A. Bonini \& D. Motta-Roth. (Orgs.) Gêneros: teorias, métodos e debates. São Paulo: Parábola Editorial, p.130-149, 2005.

COLLINS, H. \& FERREIRA, A. (orgs). Relatos de experiências de ensino e aprendizagem de línguas na Internet. São Paulo:Mercado de Letras, 2004.

DILLON, A. \& GUSHROWSKI, B. Genres and the Web:

Is the personal home page the first uniquely digital genre? Disponível em: [http://www.slis.indiana.edu/adillon/genre.html], 2000.

HALLIDAY, M.A.K \& HASAN, R. Language, context and text: aspects of language in a social-semiotic perspective. 2 ed. Hong Kong:OUP, 1989.

HERRING, S. C; Scheidt, L. A.; Bonus, S.; Wright, E. Bridging the Gap: A Genre Analysis of Weblogs. hool of Library and Information Science Indiana University, Bloomington. Acessado em Abril de 2006.

HYMES, D. Toward ethnographies of communication: the analysis of communicatiove events. In: P. P. Giglioli (Ed.), Language and social context. New York: Penguin, p.21-44, 1972.

HORTON, W. Web-based training.

Disponível em www.horton.com/DesigningWBT, 2000.

KOMESU, F. C. Blogs e as práticas de escrita sobre si na Internet. In Marcuschi, L.A et al. Hipertexto e gêneros digitais, Rio de Janeiro: Lucema, 2004.

McCARTHY, M \& CARTER, R. Language as discourse: Perspectives for language teaching. London: Longman, 1994.

MEURER, J.L. Gêneros textuais na Análise Crítica de Fairclough., In: Gêneros: teorias, métodos, debates. Meurer, J.L, Bonini, A.; Motta-Roth, D (orgs)São Paulo: Parábola editorial, 2005.

\& D. MOTTA-ROTH. Introdução. In: J.L. Meurer \& D. Motta-Roth.

(Orgs.) Gêneros textuais e práticas discursivas: Subsídios para o ensino da linguagem. Bauru, SP: EDUSC, p. 09-14, 2002. 
MOTTA-ROTH, D. Questões de metodologia em análise de gêneros. In Gêneros textuais: reflexões e ensino. Karwoski, A. M.; Gaydeczka, B.; Brito, K.S. (orgs), Palmas e União da Vitória, PR: Kaygangue, 2005.

MOTTA-ROTH, D. \& V. HEBERLE. O conceito de "estrutura potencial do gênero" de Ruqayia Hasan. In: J. L. Meurer, A. Bonini \& D. Motta-Roth. (Orgs.) Gêneros: teorias, métodos e debates. São Paulo: Parábola Editorial, p.12-28,2005.

MURPHY, E. A stranger in a stranger land: Teachers' Beliefs About Teaching and Learning French as a Second or Foreign Language in Online Learning Environments, Tese de Doutorado, 2000. Faculté des Sciences de L'éducation Université Laval Québec, 2000. Acessado em julho de 2003 http:// www. nald.ca/ fulltext/ stranger/ cover. htm

REIS, S.C. A intervenção pedagógica do professor em contextos diferenciados: a oferta de andaimes na aula de inglês presencial e a distância. Dissertação de Mestrado, Unicamp: Campinas, 2004.

RODRIGUES, R. H. Os gêneros do discurso na perspectiva dialógica da linguagem: a abordagem de Bakhtin. In Gêneros: teorias, métodos, debates. Meurer, J.L, Bonini, A. ; Motta-Roth, D (orgs), São Paulo: Parábola editorial, 2005.

ROJO, R; BARBOSA, J.P.; COLLINS, H. Letramento digital: um trabalho a partir dos gêneros do discurso, IN: Gêneros textuais: reflexões e ensino, 2005. . Gêneros do discurso e gêneros textuais: questões teóricas e aplicadas. In: Gêneros: teorias, métodos, debates. Meurer, J.L, Bonini, A. ; MottaRoth, D (orgs), São Paulo: Parábola editorial, 2005.

RUIZ, E. M.S. D. Kd o português dk gnt???;-) O blog, a gramática e o professor. In: Revista Brasileira de Lingüística Aplicada, Belo Horizonte: Faculdade de Letras de UFMG, Vol.5, no 1, p.115-133, 2005.

RUSSO, T., \& Benson, S. Learning with Invisible Others: Perceptions of Online Presence and their Relationship to Cognitive and Affective Learning, Educational Technology \& Society, 8 (1), 54-62, 2005.

TAVARES, K.C.A. Discutindo a formação do professor on-line - de listas de habilidades docentes ao desenvolvimento da reflexão crítica, [Online] 2001. URL:[http://www.educarecursosonline.pro.br/artigos/reflex.htm]. Consultado em: 20/08/2003.

MENEZES, V. L. O. P. (org). Interação e aprendizagem em ambiente virtual. Belo Horizonte, MG: Faculdade de Letras, UFMG, 2001.

WARSHAUER, M. Comparing face-to-face and electronic discussion in the second language classroom. CALICO Journal 13(2), 7-26, 1996. URL:[ http://www.gse.uci.edu/markw/comparing.html]

Interaction, negotiation, and computer-mediated learning. In $\mathrm{M}$. Clay (Ed.), Practical applications of educational technology in language learning. Lyon, France: National Institute of Applied Sciences, 1998. Disponivel em: URL:[ http://www.insa-Iyon.fr/Departements/CDRL/interaction.html]

; Kern, R. Theory and practice of network-based language teaching. In M. Warschauer \& R. Kern (Eds.), Network-based language teaching: Concepts and practice.New York: Cambridge University Press, 2000. Disponível em:URL:[ http://www.gse.uci.edu/markw/nblt-intro.html] 
\& Meskill, C. Technology and second language learning. In $\mathrm{J}$. Rosenthal (Ed.), Handbook of undergraduate second language education (pp. 303-318). Mahwah, New Jersey: Lawrence Erlbaum, 2000. Disponivel em:URL:[ http://www.gse.uci.edu/markw/tslt.html] 